\title{
Relação campo cidade em tempos de pandemia
}

\section{Countryside city relation in pandemic times}

\section{Relación campo ciudad en tiempos de pandemia}

\author{
Suzane Tosta Souza ${ }^{1}$ http://orcid.org/0000-0001-8658-0189
}

\footnotetext{
${ }^{1}$ Doutorado em Geografia pela Universidade Federal de Sergipe- UFS-Brasil, Professora do Programa de Pós-Graduação em Geografia da Universidade Estadual do Sudoeste da Bahia- Vitória da Conquista-BA-Brasil, suzanetosta@gmail.com
}

\section{Resumo}

Este artigo visa analisar a relação campo-cidade diante do contexto de expansão da pandemia provocada pela COVID19 no Brasil, defendendo que essa vem a escancarar as desigualdades espaciais, dado o conteúdo de classe e étnicoracial com que se expressa no cotidiano dos trabalhadores das periferias urbanas e das comunidades camponesas. A essa se soma um cenário marcado pela crise do capital, a ascensão de um governo de extrema direita e sua política genocida e em novas investidas sobre o trabalho, marcando os espaços de reprodução social dos sujeitos mais pobres no campo e nas cidades.

Palavras-chave: Relação Campo-Cidade. Produção desigual do espaço. COVID-19.

\begin{abstract}
This article aims to analyze the countryside-city relation in the pandemic expansion context caused by COVID-19 in Brazil, defending that it comes to emphasize the spatial inequalities, given the class and racial-ethnic content which is expressed in the daily life of urban peripheries workers and the peasants. Plus a scenario marked by the capital crisis, the ascension of a far-right govern and its genocidal policy and in new thrusts over labor, marking the social reproduction spaces of poorest subjects in the countryside and the cities.
\end{abstract}

Keywords: Countryside-City Relation. Unequal Production of space. COVID-19.

\section{Resumen}

Este artículo tiene como objetivo analizar la relación campo-ciudad ante el contexto de la expansión de la pandemia desatada por la COVID-19 en Brasil, defendiendo que esta viene a exponer las desigualdades espaciales, dado el contenido de clase y étnico-racial con que se expresa en la vida diaria de los trabajadores de las periferias urbanas y de las comunidades campesinas. Junto a esa, agrega-se un escenario marcado por la crisis del capital, la elevación de un gobierno de extrema derecha y su política genocida y en nuevas embestidas hacia el trabajo, marcando los epacios de reproducción social de los sujetos más pobres en el campo y en las ciudades.

Palavras Clave: Relación Campo-Ciudad. Producción desigual del espacio. COVID-19 


\section{Introdução}

A pandemia provocada pelo novo coronavírus, e sua forma de expressão a COVID-19 ${ }^{2}$, ocasionando um ambiente de distanciamento, isolamento social e pânico em quase todos os países do mundo, em especial no Brasil, tem levado pesquisadores e estudiosos, das diversas áreas científicas, a refletir sobre essa nova realidade, a produzir algum tipo de conhecimento que possa auxiliar nas pesquisas sobre o vírus, na prevenção, ou mesmo na forma em que esse se devolve desigualmente na sociedade.

No caso da Geografia, a pandemia veio a escancarar as desigualdades espaciais existentes em uma sociedade composta por classes sociais antagônicas, e longe de se constituir apenas em uma crise sanitária, passível de ser minimizada ou resolvida por meio da intervenção do poder público, revela a crise da forma de sociabilidade, marcada pelos interesses dos detentores dos meios de produção de não inviabilizar o processo de expansão e extração de trabalho não pago, pouco importando os sujeitos sociais que sucumbem ao vírus. Portanto, em uma sociedade pautada na produção exacerbada de mercadoria, onde todas as relações sociais passam a ser definidas pela necessidade de se manter o lucro, afere-se que a própria forma de lhe dar com o vírus vai referenciar esse conteúdo, uma vez que, como já apontado por Marx o "mundo das coisas" prevalece de maneira significativa sobre o "mundo dos seres humanos" (MARX, 1984). Essa afirmativa é destacada pelo artigo do geógrafo D. Volochko (2020) quando ao considerar a realidade da Covid-19 no Brasil aponta o "falso dilema" economia versus vida colocado pelo Governo federal. A pandemia é então vista apenas como mais uma forma de tornar explicita a contradição existente e insuperável entre capital e trabalho. No caso do Brasil, a essa situação estrutural da crise do capital, se soma a ascensão de um projeto de poder ultraconservador, que aliado das classes dominantes (capitalistas e proprietários fundiários) também coloca o lucro acima da vida, fazendo do país o

\footnotetext{
${ }^{2}$ De acordo com as indicações da Organização Mundial de Saúde (OMS) coronavírus é a denominação do vírus que causou o surto e que sofre variações como o Sars-Cov e o Mers-Cov. O Sars-Cov-2 é a nova variação do vírus, também conhecido pela imprensa e divulgado pelos especialistas como "novo coronavírus", que significa "síndrome respiratória aguda grave - coronavírus 2". A COVID-19 é a doença respiratória provocada pela infecção do novo coronavírus. (https://guiadoestudante.abril.com.br/)
} 
SOUZA, S. T.

principal epicentro da doença, atingindo em cheio a classe trabalhadora, conforme busca-se demonstrar ao longo do referido artigo.

Argumentamos, ainda, que são as relações sociais, nas suas contradições, quem determinam a realidade, assim sendo, o contexto que coloca o Brasil no epicentro da pandemia, não se restringe ao vírus em si, mas a falta de uma política séria de prevenção e isolamento, que deveria ser a prioridade do Governo Federal. Ao invés disso, o mesmo se aproveita da situação para dar continuidade a sua política genocida, que se faz com maior peso na concentração das mortes nos setores mais empobrecidos da sociedade, trabalhadores precarizados das periferias urbanas e das comunidades camponesas pobres.

Embora se possa considerar a difusão e concentração do vírus (bem como a velocidade que esse acontece) de maneira mais evidente nas grandes cidades, não podemos desconsiderar a realidade precária do sistema de saúde em parte significativa das cidades médias, e mesmo sua inexistência em cidades pequenas, distritos e comunidades rurais existentes no Brasil, em que o estágio de abandono ou mesmo de isolamento de muitas dessas, acaba por deixar a população bastante vulnerável ao vírus, e mesmo a possibilidade da morte sem nenhuma forma de acesso ao atendimento médico.

Diante desse contexto, o presente artigo aponta os desafios de se discutir sobre uma relação histórica no capitalismo, como é a relação campo cidade, em tempos de pandemia, e de refletir sobre as dificuldades concretas de reprodução social dos sujeitos sociais que vivem do trabalho, sejam os camponeses, os trabalhadores assalariados, subcontratados, temporários, informais, ou dispostos ao assalariamento, estejam esses no campo ou nas cidades.

Visa refletir, também, sobre o que esperar em um contexto pós pandemia, em uma realidade marcada pela expropriação histórica, a exploração do trabalho, o controle sobre a terra e os meios de produzir a vida, e que associados à concentração fundiária, o exacerbar da violência contra os povos do campo e os trabalhadores nas periferias urbanas, dentre outras questões, desperta naqueles que vivem do trabalho o desafio de vencer, além das formas históricas que os oprime, o vírus, para se manterem vivos e reorganizar a luta, seja pela terra, pelo trabalho, por frações do espaço urbano, pela moradia, ou mesmo à reprodução da vida.

O ritmo da cidade diminui drasticamente, assim como a produção dos pequenos produtores no campo - que embora se mantenha, sofre maiores dificuldades para ser 
SOUZA, S. T.

comercializada. Nessa conjuntura, o chamado auxílio governamental ${ }^{3}$ vem, temporariamente, no intuito de garantir as condições mínimas de reprodução dos sujeitos pobres, informais e desempregados, que se constituem parcela significativa da sociedade. Mas, efetivamente, não houve (e não há) uma política séria de distanciamento social, sobretudo para determinadas funções e trabalhos mais precarizados, que não tiveram o direito de escolher o proposto pelas organizações internacionais e nacionais de saúde. E isso coloca o Brasil diante de uma situação crítica em relação ao mundo, tornando-se o epicentro da doença, e o segundo em quantidade de mortes, respondendo, atualmente, por mais de $10 \%$ do número de óbitos pelo vírus ${ }^{4}$.

Os efeitos da pandemia são sentidos, também, em ritmos diferenciados, entre o campo e a cidade, e embora se concentrem, muitas vezes nessas últimas (as metrópoles São Paulo e Rio de Janeiro são responsáveis pelo maior número de casos de mortes no país), também se expressa no campo, sobretudo nas comunidades pobres camponesas, indígenas, quilombolas, ribeirinhas, etc., a exemplo do que denuncia a Comissão Pastoral da Terra (CPT) no Amazonas e outros estados do Norte, onde a mortalidade no interior desses e nas comunidades rurais é significativa. Neste caso, aparentemente, temse a ideia de que o fato do relativo isolamento dessas comunidades e famílias, os mantêm mais protegidos do vírus. Algo que não se confirma no país da grilagem de terras, que avança com peso total no processo da pandemia e da falta de fiscalização, em direção aos territórios dos índios e demais povos do campo, o que além de colocá-los sobre a ameaça da perda da terra, lhes deixam vulneráveis ao contágio do vírus, assim como a Organização Pan Americana de Saúde (OPAS) aponta estar acontecendo em outros países da América Latina (com a contaminação dos povos do campo e dos pobres da cidade).

\section{A relação campo-cidade, a reprodução dos sujeitos e a pandemia}

\footnotetext{
${ }^{3}$ Chamada de auxílio emergencial aprovado pela Câmara e Senado Federal a contragosto do atual Governo que inicialmente apontava a falta de recursos e posteriormente, junto ao seu Ministro da Economia Paulo Guedes, propôs um auxílio mensal de R \$200,00. No Congresso, foi aprovado na Câmara (26/03) e no Senado (30/03) o auxílio emergencial de R \$600,00 por trabalhador. O montante previsto por mês era de R \$ 60 bilhões mensais, mas, posteriormente com os PLs 873/2020 e 1.075/20 - que ampliou o direito para várias categorias de trabalhadores informais, autônomos e artistas, o recurso mensal gasto passou para algo em torno de R\$ 98,2 bilhões, total bem abaixo dos grandes montantes que o governo tem repassado as empresas, conforme pode ser observado em algumas reportagens que se teve acesso: https://agenciabrasil.ebc.com.br/economia/noticia/202004/governo-pode-liberar-recursos-extras-para-auxilio-emergen

https://www12.senado.leg.br/noticias/materias/2020/04/06/governo-libera-r-34-bilhoes-para-empresas-pagaremsalarios-na-pandemia https://www1.folha.uol.com.br/mercado/2020/06/para-destravar-credito-a-empresas-governolanca-programa-de-empr

${ }^{4}$ De acordo com reportagem publicada na Folha de São Paulo, no dia 01/07/2020, o Brasil chegou a 60.713 mortes oficiais pelo novo coronavírus, sendo mais de 1.200 óbitos nas últimas 24 horas. Aponta ainda a reportagem que o Brasil possui $2,8 \%$ da população mundial e registra $11,5 \%$ dos óbitos pela doença no mundo.
} 
SOUZA, S. T.

$\mathrm{Na}$ Ciência Geográfica, diante das transformações ocorridas nos espaços do campo e das cidades, sobretudo nas últimas décadas, tem sido maturado um importante debate sobre a relação campo-cidade, muito embora esse siga por perspectivas teóricas distintas.

Compõe aqueles que, diante da expansão urbana e da produção industrial, apontam a vitória da cidade sobre o campo e, de um modo geral, a subordinação do campo à cidade. Para tais análises dois caminhos se apresentam para o campo: ou a integração ao mercado e a produção industrial, onde os debates anteriores dos complexos agroindustriais e, mais recentemente do agronegócio como modelo produtivo para o campo ganham sentido, ou o seu desaparecimento. Em acordo a essa concepção, não há espaço para os camponeses e as formas de reprodução das comunidades tradicionais, dos povos originários, extratores, pescadores, etc, se reproduzirem no campo. Uma explicação improvável ao se considerar a realidade brasileira, latino-americana e mesmo de outros países e continentes do mundo.

Outra concepção, em geral decorrente da anterior, vai apontar a complementariedade na relação entre o campo e a cidades, em que o campo é lócus da produção agrícola, que se destina a sua transformação em mercadorias transformadas e consumidas nos espaços urbanos. Explicativa simplista e que também não dá conta de atender a realidade concreta desses espaços, e suas complexidades, no Brasil e mesmo em outros lugares do mundo.

A opção teórica assumida no referido artigo, parte da leitura e do método em Marx, e entende a relação histórica estabelecida entre esses espaços no contexto de consolidação da sociedade capitalista, e que se estabelece a divisão do trabalho voltada a subordinar, ambos os espaços à produção de capital. Para tanto se ancora no entendimento do processo de expropriação do campo e das transformações impulsionadas pela sociedade do capital, reportando ao processo de Acumulação primitiva, e que tem continuidade nas formas atuais de reprodução ampliada.

A relação-capital pressupõe a separação entre os trabalhadores e a propriedade das condições de realização do trabalho. Tão logo a produção capitalista se apóie sobre seus próprios pés, não apenas conserva aquela, mas a reproduz em escala sempre crescente. Portanto, o processo que cria a relação-capital não pode ser outra coisa que o processo de separação de trabalhador da propriedade das condições de seu trabalho, um processo que transforma, por um lado, os meios sociais de subsistência e de produção em capital, por outro, os produtores diretos em trabalhadores assalariados. A assim chamada 
SOUZA, S. T.

acumulação primitiva é, portanto, nada mais que o processo histórico de separação entre produtor e meios de produção. Ele aparece como "primitivo" porque constitui a pré-história do capital e do modo de produção que the corresponde. (MARX, 1984, p. 262. grifos nossos).

Assim, busca-se refletir sobre a relação campo cidade a partir da divisão social do trabalho estabelecida entre o campo e a cidade - ou seja partindo do conceito de divisão do trabalho em geral, tal qual apontada por Marx. - uma realidade insuperável enquanto perdurar esse modo de produção.

(...) Uma oposição crescente é vista entre esses dois espaços na medida em que a propriedade burguesa se torna relação dominante que impera sobre a sociedade, produto da relação capital. As classes que o personificam nesses diferentes espaços se tornam frações que, na medida em que seus interesses entram em conflito, lutam entre si por uma maior parcela da exploração da mais-valia. De outro lado, os trabalhadores assalariados tanto do campo quanto da cidade se encontram numa relação desumanizadora pela qual precisam se submeter à venda de sua força de trabalho para garantir sua sobrevivência (ROCHA, 2018, p. 68).

Referenda-se, ainda no analisado por Rocha (2018) que, com base em Marx, aponta os interesses e os conflitos estabelecidos entre as classes sociais dominantes do campo e das cidades, muito embora, como aponta Martins (1994) em A aliança do atraso - esses sujeitos (capitalistas e proprietários fundiários) possam se constituir nas mesmas pessoas, embora personifiquem realidades distintas.

Mas, o grande questionamento que buscamos elaborar no referido artigo é: diante do contexto de crise estrutural do capital, de investidas concretas sobre o trabalho, associado a realidade brasileira marcada por um governo de extrema direita, avanço do fascismo e mais recentemente, a expansão do novo coronavírus, que exacerba o conteúdo de classes na sociedade e que se concretiza na produção desigual do espaço: o que se apresenta para as relações estabelecidas entre o campo e a cidade? Como se pensar na reprodução social dos sujeitos que vivem nesses espaços, diante da exacerbação da crise? Até que ponto a difusão do vírus intensificará a crise e a ação do capital sobre o trabalho, no contexto atual e de pós pandemia?

Em palestra realizada de forma virtual no dia 03/04/2020, intitulada: A pandemia do coronavírus: vivemos uma crise revolucionária, Sérgio Lessa apontava, no contexto pós-pandemia, a tendência a maior automatização das relações de trabalho, posto que o capital não quer ficar mais dependente de ter que acessar os trabalhadores 
SOUZA, S. T.

para continuar a produção - e buscará desenvolver outros caminhos que consequentemente levarão ao aumento da produtividade do trabalho, diminuindo a quantidade de trabalhadores e aumentando o desemprego. Realidade que expressa o exacerbar da crise e as impossibilidades de reprodução de parcelas significativas da classe trabalhadora e camponesa, no campo e nas cidades, enquanto sujeitos assujeitados à condição de absolutamente supérfluos, conforme veremos a seguir.

\section{Grilagem, coronavírus e as tentativas de resistência da população do campo}

As contradições do avanço do capital no campo se consolida na ampliação da propriedade privada sobre a terra, mediante a expropriação dos trabalhadores e camponeses, principalmente por meio da grilagem, conforme já bastante evidenciado por pesquisadores brasileiros, a exemplo de Oliveira (2001, 2016). Na atualidade, esse processo de grilagem de terra segue a todo vapor, agora facilitado tanto pelo governo que declara abertamente "governar para os latifundiários grileiros", bem como se aproveitando da condição de fragilidade dessas comunidades diante da Covid-19 (pela dispersão, dificuldade ou mesmo ausência de acessar atendimento médico), fomenta a expropriação e o aumento das desigualdades espaciais no campo.

Como demonstra a reportagem intitulada: Indígenas, quilombolas e camponeses denunciam o aumento de ataques durante a pandemia, do Jornal Brasil de fato, do dia 15/05/20, quando as organizações do campo, da floresta e das águas se reuniram virtualmente no II Seminário Terra e Território, e denunciaram as diversas ameaças que veem sofrendo, principalmente por parte dos grileiros. Também em nota divulgada no dia 22/04/2020,

(...) "a Comissão Pastoral da Terra (CPT) denunciou os efeitos da pandemia do novo Coronavírus (Covid-19) entre os povos da Amazônia e o avanço dos garimpos ilegais, que têm se intensificando nesse período". Aponta o cenário como bastante preocupante, sobretudo pelo aumento do número de pessoas contaminadas e de morte pelo vírus, o que se agrava pelo fato dos estados da Amazônia legal não disporem de uma infraestrutura de saúde pública para atender a população, sobretudo as comunidades rurais. Soma-se a esse problema o crescimento de ações ilegais de invasão, desmatamento e predatórias de garimpos, que seguem avançando durante a quarentena, sobretudo devido a suspensão das fiscalizações. (CPT, 2020). 
SOUZA, S. T.

Uma das evidências da apropriação das terras e da grilagem no país é apontada pelos dados divulgados pelo Instituto Nacional de Pesquisas Espaciais (INPE) em que o desmatamento já havia superado em abril de 2020 (mês da reportagem e início da pandemia de Coronavírus no país) o índice de todo o desmatamento do ano de 2019.

Em pleno processo de pandemia, a Comissão Pastoral da Terra denuncia ameaças de despejo de comunidades quilombolas em Alcântara, no Maranhão; de invasões no território dos indígenas Karipuna, em Rondônia; ameaças de pecuaristas, que desmatam a floresta e áreas de igarapés, ao longo dos rios Preto e Machado, no Amazonas; a invasão de madeireiros no território Sawré My Bu, localizado no médio Tapajós, e dos territórios indígenas Munduruku, no Oeste do Pará, dentre outras.

No Amazonas, desmentindo a crença que o Coronavírus não iria proliferar com o calor das áreas tropicais, a pandemia já desbordou as limitadas capacidades médicas da metrópole de Manaus, que concentra a maior parte da população do estado. Porém a maior letalidade corresponde às mortes no interior do estado, por falta de recursos suficientes de atendimento, enquanto a doença se expande seguindo os principais rios: o Solimões, o Rio Negro, o Purus e o Madeira. É no Amazonas onde o coronavírus está vitimando mais indígenas no Brasil: Nas aldeias Tikuna, na cidade de Manaus e em Parintins. (CPT, 2020).

A nota dá conta ainda, que o estado do Amapá é o segundo em contaminação em Covid-19 da região. E que em Roraima, a invasão dos territórios dos povos Yanomamis, por mais de 20 mil garimpeiros tem servido para a difusão das doenças, com mortes letais entre os indígenas. Nesse processo, essas comunidades e seus territórios são colocadas como a bola da vez da grilagem de terra, associando-se, ainda, a destruição/apropriação da floresta amazônica e demais ambientes, para consolidar passagem "da boiada", como já amplamente divulgado no atual governo.

Tal realidade, faz apontar um cenário devastador para o campo, somando-se a concentração fundiária e a expropriação de centenas e milhares de famílias no país. Ainda no ano de 2015, Oliveira (2016) apontou a concentração de terras nas grandes

\footnotetext{
${ }^{5}$ Em reunião ministerial ocorrida no dia 22/04/2020, para tratar do inquérito do Supremo tribunal que investiga o presidente Jair Bolsonaro, seu ministro do Meio Ambiente, Ricardo Sales, afirmou que era preciso aproveitar "atenção da imprensa (...) voltada quase exclusivamente para a Covid" e "dar de baciada a simplificação", leia-se aprovar as normas para facilitar a exploração ambiental e assim deixar o caminho aberto para o grande capital, e os proprietários fundiários. Ou seja, nada mais adequado para o governo Bolsonaro que ter um ministro do meio ambiente que defende a destruição do meio ambiente. https://dialogosdosul.operamundi.uol.com.br/brasil/65509/documentos-mostram-que-rachadinha-debolsonaro-chegou-a-r-25-mil-em-mes-eleitoral
} 
SOUZA, S. T.

propriedades entre os anos de 2003 a 2010 - destacando o acréscimo de quase 100 milhões de hectares às grandes propriedades. Dando continuidade a pesquisas realizadas no campo brasileiro, o mesmo autor, recentemente, em oficina on line promovida pela CPT, realizada no 08/06/2020 ${ }^{6}$, enfatizou que o cenário atual da concentração fundiária deve se agravar, dadas às inúmeras situações de grilagem, ancorada na política do governo federal e seus aliados.

Ressalta-se que, o controle fundiário e as dificuldades concretas de reprodução das comunidades camponesas já vinham se acirrado na última década, sobretudo com o processo de criminalização da luta pela terra e das ocupações de terras, com a promulgação da Lei de organização Criminosa (n. 12.850), de 2013 e da Lei Antiterrorismo (n. 13.260), de 2016, ambas ainda no Governo Dilma Rousself (PEREIRA, 2018). E que se segue no Governo golpista de Michel Temer, como demonstrando por diversos grupos de pesquisa estudiosos do campo. Vale aqui ressaltar o Dossiê Michel Temer e a Questão Agrária, publicado na Revista OKARA, do Programa de Pós-Graduação em Geografia da UFPB e o artigo: “Ataques aos direitos dos povos do campo: ações do legislativo e executivo federal", publicado no cadernos Conflitos do Campo, da CPT, no ano de 2016, ao destacar dezenas de projetos de Lei, Medidas provisórias e outros aparatos jurídicos para frear a ação social da luta pela terra, deixando a terra e os recursos absolutamente à disposição dos grileiros de terra, do rentismo fundiário e das operações financeiras que se ampliam no campo. Um exemplo claro desse processo é a diminuição significativa das ações de ocupações e $\operatorname{assentamentos}^{7}$ que se constituíam espaços fundamentais à reprodução camponesa. Realidade que se acresce, tanto em ações de grilagem, violência e mortes no campo no Governo Jair Bolsonaro, que já declarou, em diversos momentos, governar para os grandes proprietários fundiários ${ }^{8}$.

Assim, os projetos do agronegócio se expandem no campo brasileiro, consolidando o papel do país na divisão social do trabalho - e cuja produção se

\footnotetext{
${ }^{6}$ Oficina Conflitos no Campo brasileiro. O de sempre e em tempos de bolsonarismo e pandemia realizada no dia 08/06/2020. Promovida pelo Fórum Popular da Natureza e a Comissão Pastoral da Terra. Disponível: facebook.com/forumpopulardanatureza/Fórum Popular da Natureza.

${ }^{7}$ Com base em dados da CPT, Pereira (2018) aponta que os acampamentos registrados no ano de 2005 foi de 90 , passando para 35 (2010), 27 (2015) e apenas 22 (2016). Já a ocupações registradas passaram de 437 (2005), para 180 (2010), 200 (215) e 194 (2016). No ano de 2018, a CPT registrou a existência de apenas 17 acampamentos.

${ }^{8} \mathrm{https://www.gazetadopovo.com.br/republica/bolsonaro-bancada-ruralista-agronegocio/}$ https://www.correiodopovo.com.br/not\%C3\%ADcias/rural/este-governo-\%C3\%A9-de-voc\%C3\%AAs-indicabolsonaro-\%C3\%A0-ruralistas-1.349378

https://reporterbrasil.org.br/2019/09/com-apoio-de-irmao-de-bolsonaro-ruralistas-tentam-impedir-demarcacao-deterras-indigenas-em-sp/
} 
SOUZA, S. T.

transforma, cada vez mais, em mercadorias, ativos financeiros controlados pelos mercados mundiais, conforme apontam dados do Ministério da Agricultura, Pecuária e Abastecimento.

O Brasil é o terceiro maior exportador de alimentos do mundo. Tem safras recordes e está na mira para ser o maior produtor nos próximos anos. Segundo previsões do Ministério da Agricultura, Pecuária e Abastecimento, a produção deve passar de 232,6 milhões de toneladas da safra 2017/18 para $\mathbf{3 0 2}$ milhões até 2027/28, representando um aumento de 69 milhões de toneladas (crescimento de 2,5\% ao ano). Atualmente, a área brasileira para a produção de grãos é de $\mathbf{6 3}$ milhões de hectares na safra 2018/19, e deve se expandir para 71 milhões até a safra 2027/28. Esse crescimento se baseia no aumento de 70\% da produção de grãos no país nos últimos dez anos.(informação verbal) ${ }^{9}$

Em contraposição à expansão da produção de alimento, que adquirem a forma de commodities, a fome se consolida para parcela da classe trabalhadora e camponesa, como uma expressão concreta da contradição capital versus trabalho, onde o alimento é a mercadoria a ser vendida, e não a possibilidade de sanar a fome da população.

821 milhões de pessoas no mundo ainda passam fome ( 1 em cada 9 pessoas). Ainda falta comida suficiente para a maior parte da população mundial manter uma vida saudável, de modo que $\mathbf{1 0 \%}$ da população mundial está exposta à insegurança alimentar grave.

Em 2007, 13,1\% das pessoas do mundo se encontravam em estado de desnutrição. Segundo os últimos dados da FAO, em 2017, esse percentual diminuiu para $\mathbf{1 0 , 9 \%}$, sendo que a maior parte reside na África. (Anuário Estatístico da FAO, (informação verbal) ${ }^{10}$

No Brasil, dados do IBGE apresentados em reportagem da BBC, em 19 de julho de 2019, contradizem a informação do Governo Jair Bolsonaro de que não há fome no Brasil.

Segundo a última pesquisa do órgão sobre o tema, de 2013, 3,6\% dos brasileiros têm insegurança alimentar grave. $\mathrm{O}$ índice correspondia a 7,2 milhões de pessoas no ano da pesquisa. Na definição do IBGE, em domicílios com insegurança alimentar grave, pode-se "passar pela privação de alimentos, podendo chegar à sua expressão mais grave, a fome". O IBGE não colheu dados sobre a fome no Brasil desde então. Porém, é provável que o índice tenha aumentado nos últimos anos, acompanhando o crescimento da pobreza verificado a partir de 2016. ${\text { (informação verbal })^{11}}^{1}$

\footnotetext{
9 Texto extraido de (https://blog.jacto.com.br/agricultura-mundial/).

${ }^{10}$ Texto extraido de https://blog.jacto.com.br/agricultura-mundial/).

${ }^{11}$ Texto extraido de(https://www.bbc.com/portuguese/brasil-49039151)
} 
SOUZA, S. T.

Naquele ano, 52,8 milhões de pessoas (ou 25,7\% dos brasileiros) eram consideradas pobres, número que passou para 54,8 milhões $(26,5 \%)$ em 2017. Não houve medições da pobreza desde então.

E é diante desse caráter rentista da terra, do afã do capital de se expandir no campo, transformando o trabalho e todo o seu resultado em mercadorias, que o processo de expropriação e resistência dos camponeses fazem do campo brasileiro uma expressão da contradição entre capital e trabalho, onde por um lado a terra e o trabalho se tornam mercadorias, por outro os camponeses que ainda permanecem no campo buscam formas de sobreviver ao capital, à grilagem e agora ao vírus. Ainda assim, a expropriação do campo é evidente e essa se consolida, sobretudo, na desigual produção dos espaços urbanos, sobretudo nas periferias, lócus de reprodução dos sujeitos expropriados do campo, migrantes, pobres e vendedores, exclusivamente, de sua força de trabalho.

\section{Da expropriação à reprodução da vida nos espaços da periferia urbana}

Compreendendo o processo histórico de expropriação dos povos da terra e dos instrumentos de trabalho, como uma condição fundamental a reprodução do modo de produção capitalista, é que se buscam as explicações históricas para entender os espaços de reprodução dos trabalhadores no urbano, sobretudo as periferias urbanas, produzindo um conteúdo social e histórico desigual, porque produto da expropriação, da conversão em força de trabalho e da exploração dessa para produzir mais valia. Tal realidade se intensifica com a mobilidade do trabalho em direção às periferias urbanas, frente as dificuldades no acesso ao solo urbano e as garantias de se reproduzir nesse, a luta pela moradia e pelo trabalho, como apontado por Carlos (2007). Essa realidade é aguçada no processo de pandemia provocada pela Covid-19, assim, relata a autora que:

No plano local, as políticas públicas direcionando os orçamentos distribuem desigualmente os recursos, precarizando a vida urbana que se faz com a privação do urbano e perda de direitos. Nesta escala, a segregação socio-espacial ilumina a hierarquia social que se realiza como hierarquia espacial, impondo acessos diferenciados aos lugares da cidade, pela imposição da propriedade privada, que produz e estrutura a sociedade desigual que vivemos e que vai espelhar aonde a pandemia vai atacar mais fortemente. Esse movimento em direção ao futuro se faz em detrimento do humano - que apenas sobrevive - e, agora, também da vida (CARLOS, 2020, p. 11). 
SOUZA, S. T.

Expropriados da terra e dos recursos da natureza, os sujeitos vendedores de sua força de trabalho, encontram no duro cotidiano das periferias urbanas a condição concreta de uma existência bastante limitada.

Limitação nas condições objetivas da vida que se estende o espaço da moradia, da negação a serviços públicos básicos, que em um contexto de pandemia, se apresenta com maior peso e, muitas vezes, a impossibilidade de sobreviver.

Esse cenário já se apontava e se agravava pelo menos no contexto das reformas neoliberais e no Brasil se consolida, sobretudo, na Reforma Trabalhista e na Reforma da Previdência.

Os dados apresentados pelo IBGE referentes ao desemprego no primeiro trimestre do ano de 2020, ou seja, um cenário em que a Covid-19 ainda não havia se expandido concretamente, dão conta de que: a taxa de desemprego voltou a crescer, ficando em 11,9\%, o referente a 12,9 milhões de pessoas. A pesquisa apontou para a existência de 4,8 milhões de pessoas desalentadas e uma taxa de subutilização de 24, $4 \%$, índices que se mantiveram ou aumentaram em relação aos dados do mesmo órgão que utilizamos em artigo publicado em 2019.

(...) segundo dados do IBGE/PNAD, trimestre março-maio de 2019 o número de desempregados no país era de $11,8 \%$, o equivalente a 12,6 milhões de pessoas. Entretanto, embora aponte um percentual um pouco menor que o trimestre anterior dez. 2018/fev. 2019 que foi de $12,3 \%$ atingindo 13 milhões de pessoas, o órgão de pesquisa aponta que na verdade o que ocorreu foi um aumento significativo dos trabalhadores sem carteira assinada, subutilizados e por conta própria, indicando um quadro de precarização do trabalho com recorde da série histórica que se iniciou no ano de 2012. (SOUZA e CONCEIÇÃO, 2019, p. 64).

Com a pandemia, dados do IBGE divulgados pelo Jornal o Globo, em reportagem de Gabriel Martins, dão conta que já no mês de abril, a taxa de desemprego passou para 12,6\%, atingindo 13,8 milhões de pessoas, quase um milhão a mais de pessoas apenas no primeiro mês de distanciamento e isolamento social por conta da pandemia. Destaca, ainda a reportagem, que os informais foram os mais atingidos.

Para o mês de maio, a reportagem de Alexandro Martelo, publicada no Portal G1, no dia 09/06/20, apresentando dados divulgados pelo Ministério da Economia, destaca que o país teve mais 960 mil pedidos de seguro-desemprego, totalizando, até 
SOUZA, S. T.

então, 1,9 milhões de pedidos, ou seja, quase 15 milhões de desempregados no país até o mês de maio de 2020 .

Apontando considerações feitas pela Organização Internacional do Trabalho (OIT), o jornalista Jamil Chade, destaca em reportagem publicada pela UOL, no dia 27/05/20, que o novo epicentro da pandemia será também, o epicentro do desemprego. Pode-se verificar um raciocínio exatamente contrário ao apontado pelo gestor federal, ao vincular o aumento do desemprego às questões meramente econômicas, como o fechamento das fábricas e do comércio, desconsiderando ou mesmo minimizando os efeitos da pandemia. Para a OIT e o referido repórter é exatamente a incapacidade em lidar com o vírus que vai se transformar em aumento do desemprego no Brasil. Fato que se acresce diante do agravamento da crise social, da crise do capital, com reflexos ainda mais evidentes nas desigualdades que compõem o espaço e a periferia urbana, sobretudo se somadas as dificuldades sanitárias e do não acesso a serviços básicos de saúde e materiais de higiene simples para essas populações.

Trata-se de um quadro ainda mas desolador quando se observa os efeitos concretos da Reforma Trabalhista (aprovada em 2016) e da Reforma da Previdência, que retira a possibilidade de aposentadoria para as categorias mais precarizadas da classe trabalhadora, que se reproduzem tanto nas periferias urbanas quanto nas comunidades pobres do campo. Tal realidade nos coloca diante da expansão dos processos de expropriação e de precarização do trabalho, portanto diante da ampliação das desigualdades que se expressam na produção dos espaços do campo e das cidades, do conteúdo de classes na produção do espaço e em formas precárias de reprodução dos sujeitos, como veremos a seguir.

\section{O conteúdo de classes da pandemia e na produção dos espaços do campo e das cidades}

Ao fazer uma análise do processo de expansão da pandemia do novo coronavírus, enfatizando a situação da crise do modo consumista do capital e dos rebatimentos desse processo para os trabalhadores mais precarizados, Davis et al (2020, p. 6) chama atenção para o caráter de classes no qual se expressa a pandemia, que 
SOUZA, S. T.

embora "permaneça estável e pouco mutável, seu impacto sobre os grupos etários mais jovens pode ser diferente nos países e grupos mais pobres" 12 .

Desmistificando o "mito conveniente" de que as doenças infecciosas não reconhecem classe ou qualquer outra barreira ou limite social, Harvey (2020) aponta que hoje essas diferenças de classes e os impactos sociais disso contam uma história bem diferente, que vai chamar de "discriminações costumeiras", em que:

(...) a força de trabalho que se espera que cuide dos números crescentes de doentes é tipicamente altamente sexista, racializada e etnicizada na maioria das partes do mundo. (...) Esta "nova classe trabalhadora" está na vanguarda e suporta o peso de ser a força de trabalho que corre maior risco de contrair o vírus através de seus empregos ou de ser demitida injustamente por causa da retração econômica imposta pelo vírus. Há, por exemplo, a questão de quem pode e quem não pode trabalhar em casa. Isto agrava a divisão social, assim como a questão de quem pode se isolar ou ficar em quarentena (com ou sem remuneração) em caso de contato e infecção. (...) o progresso da COVID-19 exibe todas as características de uma pandemia de classe, gênero e de raça. Embora os esforços de mitigação estejam convenientemente camuflados na retórica de que "estamos todos juntos nisto", as práticas, particularmente por parte dos governos nacionais, sugerem motivações mais sinistras (HARVEY, 2020, p. 21).

Também no sentido de descortinar o caráter de classe da pandemia, nos reportamos ao artigo intitulado Vítimas do coronavírus: a classe trabalhadora imigrante, das autoras Célia Vendramini e Soraya Conde (UFSC) que analisaram a situação dos trabalhadores e migrantes no Estados Unidos, no momento em que esse país se tornou o epicentro da doença e onde morreram mais pessoas no mundo. Esse estudo vai dar conta de que apesar da tentativa de mascarar o caráter de classes e uma possível ‘democratização' no contágio pelo vírus, aos poucos o acesso aos dados das vítimas fatais da COVID 19 apontam a condição de classe da maioria desses sujeitos, como informações sobre a moradia e a renda, que escancaram, nas diversas partes do mundo, a extrema desigualdade social decorrente da divisão de classes.

\footnotetext{
${ }^{12}$ Leia-se, por exemplo, o que vem acontecendo no Brasil, onde é elevado o índice de jovens vítimas da COVID-19 nos leitos hospitalares e mesmo no total de vítimas fatais, oscilando em torno de 22 a $30 \%$ do total, mas atingindo, por exemplo no estado de São Paulo, percentual superior a 30\% dos mortos com idade abaixo dos 60 anos. Nesse caso, é importante destacar as desigualdades sociais e as condições de vida nas quais se reproduzem esses sujeitos, a exploração do trabalho a que são submetidos, a existência de doenças pré-existentes e mesmo a alimentação inadequada e insuficiente a que tem acesso, realidade muito presente nas periferias urbanas e comunidades pobres do campo. Ver, por exemplo: https://www.poder360.com.br/coronavirus/conheca-a-faixa-etariados-mortos-por-covid-19-no-brasil-e-em-mais-5-paises-2/
} 
SOUZA, S. T.

Apontam dados sobre as mortes na cidade de Nova Iorque (epicentro do epicentro) que revelam a distinção entre os bairros e seus moradores, com mortes concentradas nos bairros Queens (37\%), Brooklyn (32\%) e Bronx (27\%) onde residem milhares de migrantes pobres, de diversas partes do mundo, sobretudo latino americanos e as maiores concentrações de negros americanos, igualmente pobres, da cidade. No outro extremo, destacam a rica Mahattan (16\%) um dos custos de vida mais caros do mundo, revelando que cada pessoa vale pelo lugar onde está. Destacam que as vítimas fatais da Covid-19 no país são pessoas ocupam "os trabalhos mais extenuantes e precários, com longas jornadas de trabalho e baixos salários. Alimentam-se mal e de forma irregular, já encontrando-se fragilizados para enfrentar a doença". A ausência de saúde pública e a xenofobia - faz com que muitos desses morram sem atendimento. (VENDRAMINI e CONDE, Jornal Desacato, 30/04/2020).

Ressaltam, ainda a situação precária dos migrantes mais empobrecidos, como os Venezuelanos expulsos do Peru, Colômbia e do Brasil - que retornam para seus país no momento de pandemia, por não contarem com nenhum auxílio nos países que se encontravam. Esses ainda recebem auxílio do governo, não tendo a mesma 'sorte' os imigrantes que buscam retornar para a Bolívia, já que a presidente (que assumiu após o golpe que retirou o Governo eleito de Evo Morales) mandou fechar as fronteiras. Já os EUA e outros países se aproveitam da pandemia para reforçar o fechamento das fronteiras, em nome da proteção de seus cidadãos, exercitando, ainda mais, sua política xenofóbica, racista e classista.

Infelizmente, o acesso aos dados oficiais no Brasil, não permite fazer uma análise mais detalhada do perfil econômico-social da maior parte das vítimas. Os dados são genéricos, quando não inviabilizados. Entretanto, a partir de alguns estudos acadêmicos, denúncias de movimentos e entidades sociais que atuam tanto no campo quanto nas cidades, denúncias das centrais de favelas, etc, nos permite aferir a intrínseca relação de contaminação e mortes de Covid-19 com tendência para essas ocorram nos setores mais pauperizados dos trabalhadores. São os pobres do campo e das cidades!

Com essa preocupação, o Grupo de Geografia Urbana Crítica Radical (GESP), lança a publicação intitulada: COVID-19 e a Crise urbana, reunindo artigos de pesquisadores de todo o Brasil sobre o contexto de crise e da Covid-19 em suas expressões, sobretudo no espaço urbano. Em comum com as publicações anteriores, os autores destacam a realidade de classes dos sujeitos que sucumbem ao vírus, 
SOUZA, S. T.

enfatizando, ainda o contexto político marcado pelo extremo conservadorismo e mesmo do avanço do fascismo e das milícias.

\begin{abstract}
A pandemia rompe o cotidiano programado de algumas classes sociais, a das classes médias e a dos ricos, mas não chega a romper a cotidianidade de outras. O cotidiano dos trabalhadores pobres em geral, dos trabalhadores informais, dos trabalhadores da viração, esse não pode parar. $\mathrm{O}$ cotidiano desigual nas periferias urbanas $\mathrm{e}$, sobretudo, o infracotidiano dos moradores das favelas e ocupações, esses não podem parar, pois se trata de grupos sociais que não possuem exatamente um cotidiano para abrir mão, não possuem a estabilidade da cotidianidade, e sua busca pela sobrevivência - que é também sua busca pelo trabalho, pela renda, pela casa própria, enfim pelo cotidiano - carrega agora o risco enorme da contaminação, do adoecimento e da morte, ao passo que realiza também a necessária manutenção dos níveis mínimos de atividade econômica capazes de dar sobrevida ao capital. (VOLOCHKO, 2020, p. 40).
\end{abstract}

Essa mesma perspectiva é apontado por Simoni (2020) no artigo intitulado: A Covid-19 e o direito à cidade dos pobres no Brasil, que com base em dados oficiais e um cuidadoso estudo cartográfico aponta o espraiamento da doença dos bairros mais elitizados da cidade de São Paulo, onde concentram os primeiros casos da doença, que segundo o mesmo compõe-se de altos executivos ligados ao mercado e ao turismo internacional e se espalha em direção as periferias, o que ocorre devido ao grande "fluxo de trabalhadores no espaço metropolitano, com uma massa de homens e mulheres impelidos a se deslocar de suas casas aos espaços da riqueza, todos os dias", deslocando o vírus para tais espaços da doença "que encontrou nas periferias e nos espaços da pobreza um ambiente muito mais favorável a sua disseminação", se constituindo, esses, verdadeiros "barris de pólvora pandêmicos" (p. 32).

Outra questão que evidencia o conteúdo de classe da difusão e espraiamento da COVID-19 na cidade de São Paulo apontada pelo autor é o descompasso entre os altos índices de casos confirmados entre os moradores dos bairros elitizados da cidade (que efetivamente tiveram acessos aos testes e atendimento médico adequado), em detrimento as poucas confirmações de casos nos bairros mais pobres, mas com os mais elevados casos de morte, demonstrando a subnotificação desses casos quando se trata dos trabalhadores pobres e evidenciando um processo de dispersão mais avançada do vírus, sob o qual o que vai denominar "neoliberalismo de milícias" encontra terreno fértil para desenvolver sua necropolítica. 
SOUZA, S. T.

Também do ponto de vista dos organismos internacionais, ressalta-se o apontado pela direção da Organização Pan-Americana de Saúde (OPAN) que ao alertar para a situação da pandemia no continente americano, ressalta a iminência de surtos recorrentes de doença, intercalados com período de transmissão limitada, ao longo de 2 anos, e como esse processo tem atingindo às classes mais pobres da sociedade, no campo e nas periferias urbanas. Destaca que as Américas já ultrapassou (no dia 24/06/20) 4,5 milhões de casos da doenças, com mais de 226 mil mortes, essas concentradas, sobretudo nos Estados Unidos (mais de 121 mil mortos) e no Brasil (mais de 50 mil mortos), mas que se espalham em regiões pobres do continente, como no México, Haiti, Republica Dominicana e outros países.

\begin{abstract}
Não superaremos esta crise sem atender às necessidades dos mais vulneráveis: os mais propensos a adoecer e os menos propensos a receber cuidados, como povos indígenas, pessoas de ascendência africana, pessoas em situação de pobreza nas áreas urbanas e populações migrantes. Se nós os negligenciarmos, correremos o risco de que os próximos dois anos pareçam os últimos meses", disse a diretora da OPAS. (OPAS, 24/06/2020).
\end{abstract}

Reforçou a necessidade de se "priorizar a detecção precoce de casos suspeitos, exames laboratoriais, seguimento de contatos e quarentena (uma situação bem distante dos trabalhadores pobres brasileiros, que muitas vezes só tem a identificação do contágio pelo vírus após a morte); bem como a importância do fortalecimento dos sistemas de saúde, considerada por ela como a "defesa mais forte contra a COVID-19, insistiu na recomendação da OPAS de que os países invistam em saúde pública pelo menos $6 \%$ do PIB, algo que "é mais relevante agora do que nunca" (recomendação que contrasta que os ideários privatistas neoliberais - que almejam repassar esses serviços com destaque a saúde e a educação - para o grande mercado). Destaca, assim, a diretora da OPAS que são os migrantes e pessoas que dependem da economia informal todos os dias para sobreviver, os mais vulneráveis a Covid-19 e os menos propensos e receber cuidados.

Logo no início da Pandemia, a professora Larissa Bombardi ${ }^{13}$, tomando por referência estudos realizados em outros países do mundo, alertava para o fato de que as condições sanitárias no Brasil levassem para uma explosão desses casos nas comunidades e populações mais vulneráveis, que sequer tem acesso ao saneamento

\footnotetext{
${ }^{13}$ Em atividade on line realizada no mês de março e organizada pelo Grupo de Pesquisa Geografia do Trabalho
} (CEGET/UNESP-PP). 
SOUZA, S. T.

básico. Pesquisas destacavam a sobrevivência do vírus nas fezes por semanas, o que aliado as condições sanitárias, a falta de planejamento, a pouca circulação de ar entre as casas - já apontava um cenário catastrófico caso não se fossem tomadas medidas efetivas de controle e distanciamento, fato que vem se confirmando. Em resposta a essa grave problemática social o Senado Federal responde com a aprovação, por meio de sessão virtual, realizada no dia 24/06/2020, do Novo marco legal do saneamento ${ }^{14}$, dando um passo fundamental em direção a privatização desses serviços, que agora transformados em mercadoria só serão viabilizados para os sujeitos que tiverem condições de pagar por eles, agravando as desigualdades já existentes.

Uma das expressões mais gritantes da política genocida do Governo Federal vem à tona com a fala do presidente de que "alguns vão morrer" ("E daí?"), demonstrando um absoluto descaso, para não dizer deboche, para com as vítimas fatais da Covid-19 e seus familiares. Entretanto, não se trata de uma postura ingênua, ou inconsequente, mas de uma realidade por meio da qual sua necropolítica se efetiva, ao se 'praticamente' definir (e corroborar) os trabalhadores pobres quem vão morrer e aqueles outros que ao sobreviver a pandemia darão continuidade ao processo de exploração do trabalho pelo capital. Pouco importa quantos serão o que efetivamente interessa é dar continuidade a produção da riqueza e aumentar ainda mais o fosso entre as classes, reproduzindo os sujeitos em seus devidos lugares.

A fim de enfatizar o caráter de classe e a agudização das desigualdades espaciais, buscamos levantar informações sobre as categorias de trabalhadores que mais tem se contaminado, ou encontram-se em maior eminência de precarização da sua força de trabalho. Nesse processo, destaca-se a situação dos entregadores Uber Eats, aqueles que estão assumindo grande parte da circulação para o consumo de alimentos daquela parcela da população que se encontram, total ou parcialmente, em distanciamento social, mas que não dispõem da segurança mínima nas suas condições de trabalho, dos equipamentos que devem ser fornecidos pela empregadora que explora de sua força de trabalho, estando expostos a riscos constantes. Nesse sentido, nos deparamos com uma denúncia publicada pelo jornalista Leonardo Sakamoto, no portal UOL, no dia 15/04/2020, em que uma sentença sobre as condições de trabalho apontava que:

Muitos trabalhadores nem voltam para casa, dormindo na rua, por terem que trabalhar muito para poderem receber o suficiente da plataforma para sustentarem suas famílias. Imagine suas condições de

\footnotetext{
${ }^{14}$ https://www12.senado.leg.br/noticias/materias/2020/06/24/senado-aprova-novo-marco-legal-do$\underline{\text { saneamento-basico }}$
} 
SOUZA, S. T.

higiene", afirma Eliane Lucina, procuradora do Trabalho responsável pela ação. "Por isso, a distribuição de álcool gel, em larga escala, é tão fundamental. Isso pode ajudar a evitar contágio." "Os trabalhadores de empresas de transporte de mercadorias por plataformas digitais acabam exercendo papel de grande relevância no isolamento social recomendado pelos especialistas de saúde, vez que o recebimento em casa de medicamentos, alimentos e outros produtos, através do sistema delivery, auxilia na redução da circulação de pessoas", afirma Josiane Grossl, juíza da $73^{a}$ Vara do Trabalho de São Paulo, em sua decisão. "Os que realizam as entregas ficam expostos ao contágio do Covid-19 e, em razão disso, necessária a tomada de medidas a fim de reduzir o risco de propagação do vírus entre estes trabalhadores", afirma. Decisões liminares semelhantes haviam sido proferidas contra as empresas que administram a iFood e a Rappi, mas foram derrubadas por recursos na justiça ${ }^{15}$.

Somada a situação dos entregadores ifoods, motoristas de aplicativos, trabalhadores da limpeza pública, e mesmo no ambiente dos hospitais, e várias outras categorias precarizadas que, no geral, não tiveram direito ao distanciamento social, verifica-se, claramente, o acirramento das desigualdades espaciais, do caráter de classe e étnico-racial da pandemia, expresso, ainda, na paralização dos trabalhadores Uber Eats realizada no dia 1 de julho, esgarçando as contradições existentes entre capital e trabalho, e que nessa forma de sociabilidade não será superada.

\section{Considerações finais}

O artigo buscou provocar a discussão sobre a forma desigual na qual a Covid-19 se desenvolve no Brasil, sobretudo no que se refere ao número de vítimas fatais, e seu caráter de classe e étnico-racial, permitindo compreender suas expressões nos espaços do campo e da cidade. Embora aponte a concentração desses casos nos espaços das periferias, sobretudo das grandes cidades brasileiras, considera também a realidade do campo, em que a dispersão em que vivem e o abandono em tempos de pandemia, os deixam vulneráveis à ação dos grileiros de terra e da Covid-19, fato que se acresce nas dificuldades de se obter qualquer forma de atendimento médico. Nesse caso, além de contaminados esses sujeitos correm os riscos concretos da expropriação da terra de trabalho. Nos bolsões de miséria das periferias urbanas, lócus de reprodução dos trabalhadores mais precarizados, a política genocida segue a todo vapor, seja pela

\footnotetext{
${ }^{15}$ https://noticias.uol.com.br/colunas/leonardo-sakamoto/2020/04/15/coronavirus-justica-demanda-queuber-eats-proteja-saude-de-entregadores.htm? cmpid=copiaecola\&cmpid=copiaecola
} 
SOUZA, S. T.

exploração do trabalho, os assassinatos, sobretudo dos jovens negros, e agora a Covid19.

A essa doença, se acresce o contexto da crise estrutural do capital, suas investidas perversas sobre o trabalho, e a necropolítica encabeçada pelo governo federal, que agora adquire o caráter de escolher quem morre e quem vive. Ao capital, pouco importa quantos sujeitos do campo e das cidades, trabalhadores pobres e camponeses vão morrer, o que efetivamente interessa é recompor os patamares da acumulação no contexto pós-pandemia.

Portanto, conforme apontado por Carlos (2020 p. 15) “(...) é preciso considerar que o mundo pós-pandemia continuará a ser capitalista, pois não estamos vivendo uma revolução social capaz de mudar a face do mundo" o que nos coloca, sobretudo os trabalhadores mais precarizados, na luta pela sobrevivência, e no desafio da organização política e da resistência para retomar as lutas históricas da classe trabalhadora. Assim, há que se sobreviver ao vírus, derrotar o fascismo, sem perder de vista a superação dessa forma de sociabilidade.

\section{Referências}

BARBOSA, Rafael. Conheça a faixa etária dos mortos por Covid-19 no Brasil e em mais 5 países. In: PODER 360. 04/06/2020. Disponível em: https://www.poder360.com.br/ coronavirus/conheca-a-faixa-etaria-dos-mortos-por-covid-19-no-brasil-e-em-mais-5-paises-2/

BERNARDES, José Eduardo. Indígenas, quilombolas e camponeses denunciam o aumento de ataques durante a pandemia. In: Jornal Brasil de Fato, 15/05/20. Disponível em:

https://www.brasildefato.com.br/2020/05/15/indigenas-quilombolas-e-camponeses-denunciamaumento-de-ataques-durante-a-pandemia

BOMBARDI, Larissa Mies. Dupla destruição do direito à vida: interposições entre agrotóxicos e COVID-19. Mesa virtual realizada pelo CEGET, 28/04/2020. Disponível em: https://www.facebook.com/redeceget/

CARLOS, Ana Fani Alessandri. (Coord.). COVID-19 e a crise urbana [recurso eletrônico]. São Paulo: FFLCH/USP, 2020.

CARLOS, Ana Fani Alessandri. A "Revolução" no cotidiano invadido pela pandemia. In:CARLOS, Ana Fani Alessandri. (Coord.). COVID-19 e a crise urbana [recurso eletrônico]. São Paulo: FFLCH/USP, 2020.

CARLOS, Ana Fani Alessandri. A questão da cidade e do campo: teorias e política. Mercator. Fortaleza, v. 3, n. 5, nov. 2008. ISSN 1984-2201

CHADE, Jamil. Novo epicentro da pandemia, Brasil caminha para ser o epicentro do desemprego. Jornal UOL. Disponível em: https://noticias.uol.com.br/colunas/jamilchade/2020/05/27/epicentro-da-pandemia-brasil-caminha-para-ser-epicentro-dodesemprego.htm?cmpid=copiaecola) 
SOUZA, S. T.

COMISSAO PASTORAL DA TERRA. Nota pública - Amazônia diante da pandemia. CPT, 22 de abril de 2020.

DAVIS, Mike. Et. Al. Coronavírus e a luta de classes. Terra sem Amos, Brasil, 2020.

ETIENE, Clarissa F. Países devem se preparar para enfrentar surtos recorrentes de COVID-19 pelos próximos 2 anos. Organização Pan Americana de Saúde (OPAS), $24 / 06 / 2020$.

FELLET, João. Os dados contradizem as informações de Bolsonaro de que não há fome no Brasil. BBC News Brasil em São Paulo, 19/07/19. Disponível em:

https://epocanegocios.globo.com/Brasil/noticia/2019/07/os-dados-que-contradizem-afirmacaode-bolsonaro-de-que-nao-ha-fome-no-brasil.html

HARVEY, David. Política anticapitalista em tempos de COVID-19. In: DAVIS, Mike. Et. al. Coronavírus e a luta de classes. Terra sem Amos, Brasil, 2020.

LESSA, Sérgio. A pandemia do coronavírus: vivemos uma crise revolucionária. Disponível em: https://www.youtube.com/watch?v=HleZZr1vw-s

MARTELO, Alexandro. Seguro-desemprego: país tem 960 mil pedidos em maio: total durante a pandemia vai a 1,9 milhão. In: Portal G1 globo.com. 09/06/2020. Disponível em:

https://g1.globo.com/economia/noticia/2020/06/09/brasil-registra-960-mil-pedidos-de-segurodesemprego-em-maio-com-alta-de-53percent.ghtml

MARTINS, Gabriel. Com pandemia desemprego sobe para 12,6\% em abril. Informais são os mais atingidos. Jornal o Globo, 28/05/2020. Disponível em:

https://oglobo.globo.com/economia/com-pandemia-desemprego-sobe-para-126-em-abrilinformais-sao-os-mais-afetad

MARTINS, José de Souza. O poder do atraso. Ensaios de Sociologia da História lenta. São Paulo: Hucitec, 1994.

MARX, Karl. Manuscritos Econômico-Filosóficos. São Paulo: Boitempo Editorial, 2004.

MARX, K. O Capital. Crítica da Economia Política. Volume I. Livro Primeiro. O Processo de Produção do Capital. Tomo 2 (Capítulos XIII a XXV). Apresentação: Jacob Gorender. Coordenação e revisão de Paul Singer. Tradução de Regis Barbosa e Flávio R. Kothe. São Paulo: Abril Cultural, 1984. (Os economistas).

MITIDIERO JUNIOR, Marco Antonio. (et. al.). Ataques aos direitos dos povos do campo: ações do legislativo e executivo federal. In: Conflitos no Campo Brasil 2016. Goiânia: CPT Nacional - Brasil, 2016. 232 p. ISSN 1676-661X (p. 88-104).

OKARA Geografia em debate. Dossiê Michel Temer e a Questão Agrária. Vol. 12, n. 2, 2018.

OLIVEIRA, Ariovaldo Umbelino de. A agricultura camponesa no Brasil. São Paulo: Contexto, 2001.

OLIVEIRA, Ariovaldo Umbelino de. Camponeses, Indígenas e quilombolas em luta no campo: a barbárie aumenta. In: Cadernos Conflitos no Campo 2015. CPT Nacional - Brasil, 2016. (p. 28-42).

PEREIRA, Lara Barros. O processo de criminalização dos movimentos sociais em luta pela terra frente as investidas do capital na (re)produção camponesa. Monografia (Graduação em Geografia. Departamento de Geografia. Universidade Estadual do Sudoeste da Bahia, 2018. 
SOUZA, S. T.

ROCHA, Fátima Crislaine Batista Rocha. Trabalho, divisão do trabalho e oposição entre campo e cidade na produção do espaço. Dissertação (Mestrado em Geografia). Programa de Pós-Graduação em Geografia. Departamento de Geografia. Universidade estadual do Sudoeste da Bahia, 2018.

SAKAMOTO, Leonardo. Coronavírus: Justiça demanda que Uber Eats proteja saúde de entregadores. Portal UOL. Disponível em: https://noticias.uol.com.br/colunas/leonardosakamoto/2020/04/15/coronavirus-justica-demanda-que-uber-eats-proteja-saude-deentregadores.htm

SENADO FEDERAL. Senado aprova novo marco legal do saneamento básico. 24/06/2020. Disponível em: https://www12.senado.leg.br/noticias/materias/2020/06/24/senado-aprova-novomarco-legal-do-saneamento-basico

SIMONI, César. A Covid-19 e o direito à cidade aos pobres no Brasil. In: CARLOS, Ana Fani Alessandri. (Coord.). COVID-19 e a crise urbana [recurso eletrônico]. São Paulo: FFLCH/USP, 2020.

SOUZA, Suzane Tosta Souza; CONCEIÇÃO, Alexandrina Luz. Avanço do capital e a barbárie societal no campo brasileiro. In: Revista Geopauta. V. 3, n. 3, 2019. ISSN: 2594-5033.

VENDRAMINI, Célia; CONDE, Soraya. Vítimas do coronavírus: a classe trabalhadora imigrante. In: Jornal Desacato, 30/04/2020. Disponível em: http://desacato.info/vitimas-docoronavirus-a-classe-trabalhadora-imigrante-por-celia-vendramini-e-soraya-franzoni-conde/

VOLOCHKO, Danilo. O cotidiano dos pobres não pode parar: a pandemia e a necrodemografia do capital. In: CARLOS, Ana Fani Alessandri. (Coord.). COVID-19 e a crise urbana [recurso eletrônico]. São Paulo: FFLCH/USP, 2020.

YUKARI, Diana. Número de mortos pelo novo coronavírus no Brasil passa de 60 mil. Folha de São Paulo, 01/07/2020. Disponível em:

https://www1.folha.uol.com.br/equilibrioesaude/2020/07/numero-de-mortos-pelo-coronavirusno-brasil-passa-de-60-mil.shtml

Texto do Artigo é resultante da participação na mesa redonda: Dinâmicas campo-cidade: como essa relação se estabelece na pandemia, ocorrida no dia 26/06/2020 e promovida pelo Centro Acadêmico de Geografia da UFS/Campus de Itabaiana/SE. 